\title{
TWO-DIMENSIONAL PHYSICAL MODELLING IN THE ESTUARIES OF AUR RIVER
}

\author{
Achmad Syarifudin ${ }^{1)}$, Lindawati ${ }^{2)}$, Yulinatini Eka Putri ${ }^{3)}$, and Henggar Risa Destania ${ }^{4)}$ \\ ${ }^{1}$ Civil and Environmental Engineering Faculty, Universitas Bina Darma, Indonesia \\ ${ }^{2,3}$ Civil and Computer Engineering Faculty, Baturaja University, Indonesia \\ ${ }^{4}$ Civil Engineering Faculty, Indo Global Mandiri University, Indonesia \\ ${ }^{1}$ Jl. Jend. A. Yani No. 3 Palembang, 30264 \\ ${ }^{2,3}$ Jl. Kiratu Penghulu No. 02301 Baturaja, 32111 \\ ${ }^{4}$ Jl. Jend. Sudirman Palembang, 30129 \\ E-mail: syarifachmad6080@yahoo.co.id ${ }^{1)}$, lindaunbara@gmail.com²),yully_ubr@yahoo.co.id ${ }^{3)}$, \\ henggarrisa89@gmail.com ${ }^{4}$
}

\begin{abstract}
Musi River is the main river with a river length of more than $750 \mathrm{~km}$ and the average width of $540 \mathrm{~m}$ which is still affected by the tides of seawater from the thirteen existing river basin systems. Aur River is one of a tributary of the Musi River located in the Seberang Hulu area of Palembang city. Aur River needs to do research related to the rise in water level in the river body if extreme rainfall occurs that will cause inundation in the upstream area of the river. The study was conducted with a hydraulic model approach that is using a physical model of the channel with a scale model and data from existing prototypes and with the existing conditions and the running time of the model carried out for 1.50 hours with a certain period of time data collection is carried out both erosion and sedimentation data and later obtained patterns and the total amount of bed load at the estuary of river. The results of river erosion and sedimentation patterns later. The result of the research was sediment transport patterns with three times period are 30 minutes, 60 minutes and 90 minutes so that the formed of erosion and sedimentation pattern with the total bed load be range 0.66 cubic meter per day from formula, 6.34 cubic meter per day from Einstein's \& Lane and 7.48 cubic meter per day from MPM formula.
\end{abstract}

Keywords: Aur River, Standard Flume, Scale Model

\section{INTRODUCTION}

Musi River is the main river with a river length of more than $750 \mathrm{~km}$ and the average width of $540 \mathrm{~m}$ which is still affected by the tides of seawater from the thirteen existing river basin systems. Aur River is one of the tributary of Musi river basin which has affected by the fluctuation of water in Musi River and human factors such as the existence of water buoys in river bodies such as pillars, abutments and so forth.

Dynamic nature of the river, a time will be able to affect the damage to the buildings around it. Palembang's physiographic region lies in the lowlands of flood plains and includes the potential sediment areas as a pool of water. Potentials of this pool are factors that need to be considered for most areas of Palembang city (Chalov, 2011). Changes in the river generally occur due to natural factors or human factors such as the existence of water buildings in the river body such as pillars, abutments, bending and so forth. Dynamic nature of the river, a time will be able to affect damage to existing buildings nearby.

One of the problems that occur in the river is sedimentation. Sedimentation process runs very complex, beginning with the rain water that produces kinetic energy as the beginning of the process of erosion on the soil surface. When the soil becomes a fine particle, some will be left behind and the other part is carried by the stream and then into the water or river body so that it becomes sediment transport. (Walling \& Collins, 2016)

Based on the research, the greater the discharge flowing then the sediment transport (bed load) will be more and more. The complexity of the river system can be seen from various constituent components of the river, for example the shape of the river channel and branching, river bed form, river morphology, and river ecosystem. River branching will resemble a river tree starting from the first order to the $\mathrm{n}^{\text {th }}$ order. The basic river formation when examined at a glance is very difficult to hold identification and characteristics. The shape of the meander groove is influenced by the longitudinal slope of the landscape, the type of river bed material, and the vegetation in the area (Shu et al., 2015; Gurnell et al., 2016).

The sediment is at a certain time will be deposited in a place. Sedimentation can occur in river bodies or river estuaries. In connection with the above, it is necessary to conduct experimental studies on the movement of sediments on open channels (Zhang et al., 2014). 


\section{FOCUS AND SCOPE}

In a channel with a mobile bed base (a non-moving cohesive sedimentary material), there will be an interaction between the flow on the ground as shown in Figure 1, Flow changes may lead to a change in the basic configuration (roughness height). And conversely, the change of roughness will affect the flow itself.

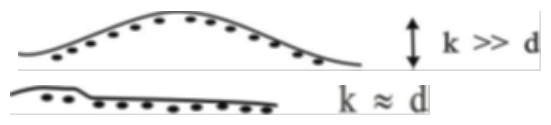

Figure 1. Due to The Flow of Sand Waves Occur

The basic configuration type depends on the nature of the flow and the material of the basic material (sand, gravel). In the open channel, the Froude, Fr, is often used as a flow criterion. For the purpose of classification of basic configuration (bed form), distinguished three regime flow, namely (Collinson, 2019):

1. Lower flow regime $(\mathrm{Fr}<1)$

2. Transition flow regime $(\mathrm{Fr} \gg 1)$

3. Upper flow regime $(\mathrm{Fr}>1)$

The ideal form of basic configuration occurs when a). The flow velocity is still very small, the frictional stress, b). The to, from the bottom is still not exceeded and the sediment material is not / has not moved so that the basic sediment is still flat (plane bed).

This phase begins to occur sediment transport, and then pellets will move rolling, sliding or jumping randomly to space and time, If the sediment material is smooth, saltation, clouds, and suspended load may occur. As the speed increases, the intensity of the sediment transport increases, and a basic configuration is established. The basic configuration form that occurs in the lower flow regime usually has characteristics such as the dunes. The shape of the hill - the dunes are often known as ripples or dunes. Figure 2. shows the basic configuration of the sedimentation channel with the shape of the Ripple dunes, Figure 3 shows the basic configuration of the sedimentation channel with Dunes dune shape, and Figure1 Shows the basic configurations channels that undergo sedimentation with the form of Bars sand dunes.

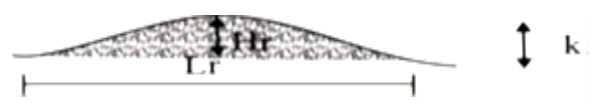

Figure 2. Forms of Ripple Sand Hill

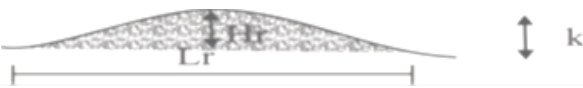

Figure 3. Forms of Sand Dunes

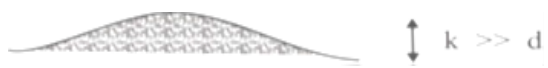

Figure 4. The shape of Sand Hills Bars
Bars are usually formed at large discharge times and will appear as small islands at a small discharge (shallow water).

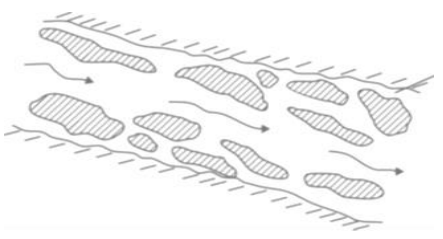

Figure 5. Dunes Shape Bars

The steep slope on the downstream side of the dunes causes the separation of the flow, so that the sand dune moves downstream and joins (into one) with the dunes downstream. So the length of dunes increases, the peak horizontal (bars), and the shape roughness decreases as shown in Figure 6.

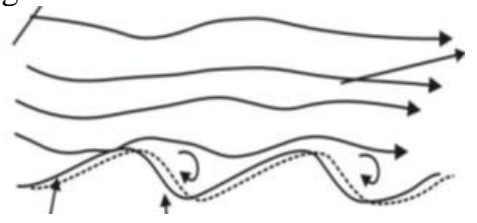

Figure 6. Erosion and Sediment Mechanisms

Between the lower flow regime and the upper flow regime, there are transition conditions. In this condition dunes like cleaned (flushed). Basic irregular configuration of dunes to flat / plane bed.

This goals of the research are the influence of water velocity the sediment pattern, the sediment pattern conditions caused by weak water velocity will cause sediment particles with a larger size to be more easily deposited while smaller sediment particles will be deposited and The amount of sediment transport that occurs at the Aur River.

\section{MATERIAL AND METHOD}

If the flow rate continues to increase, the upper flow regime will be achieved. The first configuration forms observed were plane bed (sheet flow), $\mathrm{k} \gg \mathrm{d}$. As the velocity continues to increase, the water surface becomes unstable, and the bottom of the plane bed is changed to form anti-dunes sand waves.

If the Froude number is not too large (though Fr > 1), the water level is only wavy (anti-dunes standing wave), but if Fr is very large, the wavy surface will grow, become unstable and break (anti-dunes breaking wave). When this happens, the anti-dunes form is damaged, and the base becomes flat again. Very strong anti-dunes activity will produce chutes \& pool flows.

When the dunes become one, the sand dunes will be very large by the size of the channel width. This form is known as the bars. Bed forms classification and other information on bed material sedimentation are shown in Table 1 
Table 1. Classification of bed form and other information

\begin{tabular}{|c|c|c|c|c|c|}
\hline Flow regine & Bedform & $\begin{array}{c}\text { Bed material } \\
\text { concentrations, ppm }\end{array}$ & $\begin{array}{c}\text { Mode of sediment } \\
\text { transport }\end{array}$ & $\begin{array}{c}\text { Type of sediment } \\
\text { transport }\end{array}$ & $\begin{array}{l}\text { Roghness, } \\
\quad C / \sqrt{g}\end{array}$ \\
\hline Lower regime & $\begin{array}{l}\text { Ripples } \\
\text { Ripples on dunes } \\
\text { Dunes }\end{array}$ & $\begin{array}{l}10-200 \\
100-1,200 \\
200-2,000\end{array}$ & Discrete steps & $\begin{array}{l}\text { Form roughness } \\
\text { predominates }\end{array}$ & $\begin{array}{l}7,8-12,4 \\
- \\
7,0-13,2\end{array}$ \\
\hline Transition & Washed-out dunes & $1,000-3,000$ & & Variable & $7,0-20,0$ \\
\hline Upper regime & $\begin{array}{l}\text { Plane beds Antidunes } \\
\text { Chutes and pools }\end{array}$ & $\begin{array}{l}2,000-6,000 \\
2,000- \\
2,000-\end{array}$ & Continuous & $\begin{array}{l}\text { Grain roughness } \\
\text { predominates }\end{array}$ & $\begin{array}{l}16,3-20 \\
10,8-20 \\
9,4-10,7\end{array}$ \\
\hline
\end{tabular}

The various forms of sediment build-up occurring at the bottom of the channel are shown in Figure 7.

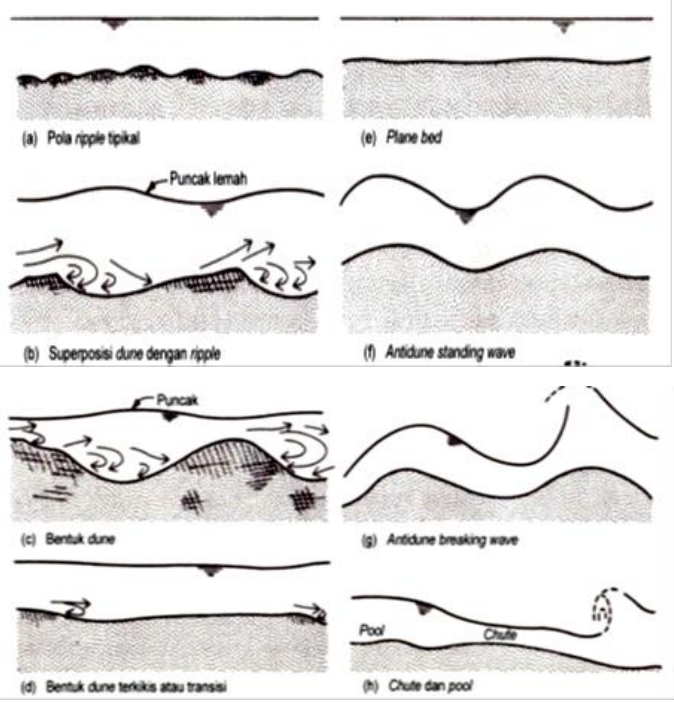

Figure 7. Form of Sediment Stacking on Channel Basis

The various basic sediment surface forms that occur at the bottom of the channel based on the type of flow that flows on the channel are shown in Figure 8.

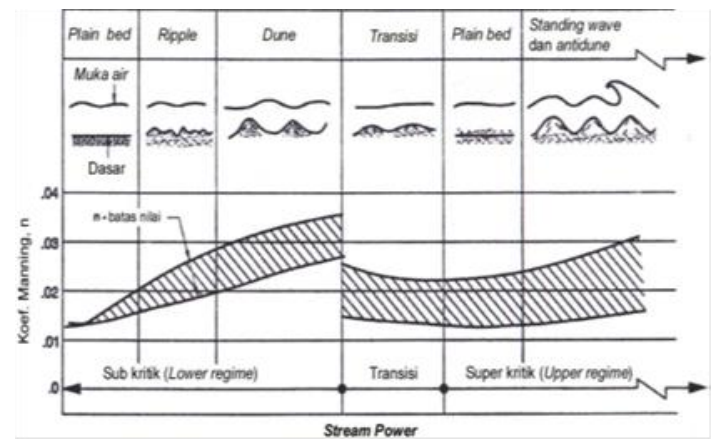

Figure 8. The Surface Form of Sediments Corresponds to The Type Of Flow That Flows On The Channel

The relationship between space and time between erosion and the accumulation of sediments occurring due to erosion taking into account the processes occurring within the channel, including: The profile extends the channel, Cross section shape and channel flow type, Basic types of drainage and soil basic sediment channel (bed load), Grain of sediment. Sediment transport according to the origin of the base material is differentiated into load of basic material (bed material load) and wash load. (Syarifudin, 2017)

The load can be a basic load (bed load) or a load of suspended load. Base load moves at the bottom of the channel by rolling, sliding or jumping, leaving no foundation. The effective energy coefficients required to be able to drive suspension sediments by utilizing the energy produced by turbulent flow, can be defined as the ratio of energy required of suspension sediments to the energy produced by turbulent flow to drive sediment the suspension. (Ikhsan, 2017)

The river is a long groove above the earth's surface where water flows from rain and is always touched by water flow and naturally formed. River or open channel is a channel where water flows with free water. In open channels, such as rivers (natural channels), the flow variables are highly irregular to space and time. These variables are channel cross section, roughness, base slope, flow discharge turn and so on. (Syarifudin, 2017)

A river channel can be divided into three parts. The three parts are upstream, middle and downstream. River upstream is a conservation area and also an erosion source area because it has a large slope (greater than 15\%). Grooves in the upstream area usually have a greater speed than the downstream, so that when flooded the material produced by erosion is not only particles the sediment is fine but also sand, gravel and even rocks.

The middle section is a transitional area of the upstream and downstream parts. The river base is more sloping so the relative flow velocity is smaller than the upstream part. This section is a balance area between erosion and sedimentation processes that vary greatly from season to season.

Downstream riverbed is usually through plains that have a sloping slope of the river bottom so that the flow velocity is slow. This situation causes some places to become flooded areas (inundation) and facilitates the formation of sediments or sediments. The precipitate is 
usually formed of fine sand deposits, mud, organic precipitate, and other very stable deposits.

The issue of the river that is always interesting to be studied is the sediment transport process, both the bed load and suspended load. Floating charge is the basic material that moves floating in the fluid flow and the motion of the grain is very dependent on fluid turbulence. (Lamchuan, 2020)

If the sediment transport rate in the river exceeds the balance limit, it will cause problems for:

1. Irrigation facilities, namely reducing the flow capacity of irrigation channels, hamper operational irrigation buildings and reduce reservoir capacity

2. River transportation facilities, because it makes the river shallow

3. In large numbers (resulting from volcanic eruptions), it can endanger environmental security

There are two kinds of sediment transport, namely fluvial movement (fluvial movement) and mass movement. The fluvial movement pattern, the forces associated with the sediment movement on the bottom of the river basin consist of gravitational and shear force components. If the tensile force generated by the water is greater than the critical gravity of the sediment grain, or in other words the shear rate of flow is greater than the shear grain shear rate, the sediment grains will move. The part of the river influenced by the fluvial flow is called the sediment flow region (sediment flow region). Generally, such a region has a flow rate of 3 and the slope of the base is more gentle than $1 / 30$.

Sediment mass movement is referred to as debris flow, that is sediment flow in the form of sediment mixture of various grain size, can occur in river channel which has a slope greater than 150 . In general, streams with a flow rate of less than 3 with a steeper slope than 1/30 are classified as a flowing region of the sediment (debris flow region).

One of the problems that happened to Sekanak River is sedimentation. Sedimentation process runs very complex, preceded by the decrease of rainwater that produces kinetic energy as the beginning of the process of erosion on the soil surface. When the soil becomes a fine particle, some will be left behind and the other part is carried by the stream and then into the water or river body so that it becomes sediment transport.

\subsection{Research Location}

Cases of this research was Aur river such as below figure 9 .

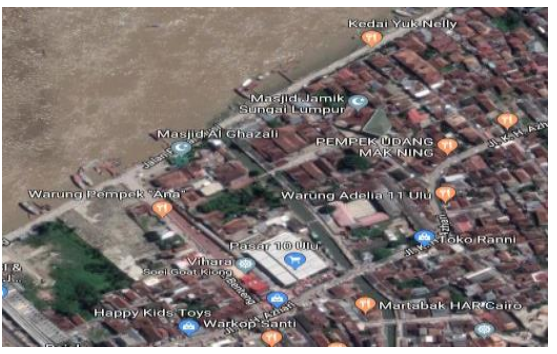

Figure 9. Research Location
This research was conducted by using simple flume physical model (figure 10) and using tools and materials that are used for the manufacture of channels and observations during the simulation took place.

Water used in this research is water obtained from Hydraulic Laboratory and Water Resources Department of Civil Engineering, Faculty of Engineering, Universitas Bina Darma. The sedimentary material used is the sandstone sediments of the king then the sand is washed and dried to clean from the mud and the dirt and sand used as later sieved with the sieve number 20 .

Open channel standard flume It is a major tool in hydraulic jumping, scouring and sediment experiments. This volume, most of the components are made of glass and have important parts, namely: Waterways, the main place in this experiment, to drain water. Form of water flume with size $400 \mathrm{~cm}$ x $20 \mathrm{~cm} \times 15 \mathrm{~cm}$.

Transparent walled water channel to facilitate observation, a reservoir that functions to hold water that will flow to the flume or out of the channel, Water pump, serves to pump water to be distributed along the gutter. This pump is equipped with automatic on / off button for power supply $220 / 240 \mathrm{~V}, 50 \mathrm{~Hz}$.

Discharge faucet, is a faucet that functions to regulate the size of the discharge coming out of the pump have a 6-9 range discharge opening scale, the tilt adjusting wheel, located on the upstream and downstream channels that can be rotated manually to adjust the desired slope of the bed bed. The bed slope regulating wheel has a scale for maximum positive bed slope $+3.0 \%$ and maximum negative bed slope $-1.0 \%$

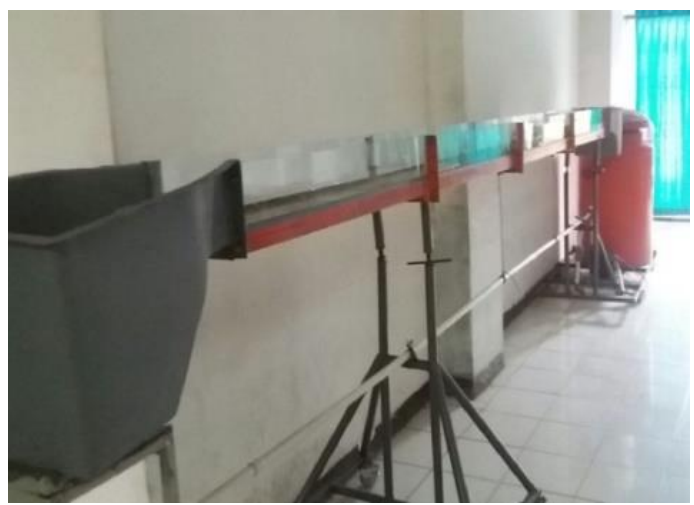

Figure 10. Open Channel Standard Flume

\section{DISCUSSION}

Analysis of mud content was conducted to find the percentage of mud content contained in the river body, and the result of mud content analysis was found to be 9.70\%, which means that the mud content in the Aur River mostly contained of mud. From the results of the calculation of basic sediment transport carried out by using the formula MPM, Einstein and Lane, Frijlink obtained results likes the table 2 . 
Table 2. Total Bed Load For Each Sediment Transport Formula

\begin{tabular}{|c|c|c|c|}
\hline Location & $\begin{array}{l}\text { MPM } \\
\text { Tb } \\
\left(\mathrm{m}^{3} / \text { day }\right)\end{array}$ & $\begin{array}{l}\text { Einstein } \\
\text { and Lane } \\
\text { Tb } \\
\left(\mathrm{m}^{3} / \mathrm{day}\right)\end{array}$ & $\begin{array}{l}\text { Frijlink } \\
\text { Tb } \\
\left(\mathrm{m}^{3} / \mathrm{day}\right)\end{array}$ \\
\hline $\begin{array}{l}\text { Aur river } \\
\text { upstream }\end{array}$ & 7.48 & 6.34 & 0.66 \\
\hline $\begin{array}{c}\text { Front of bridge } \\
\text { pillar }\end{array}$ & 37 & 34.13 & 6.9 \\
\hline
\end{tabular}

The result of observation of erosion and sediment patterns and the part of the division of three times period are 30 minutes, 60 minutes and 90 minutes so that the formed of erosion and sedimentation pattern as in figure below.

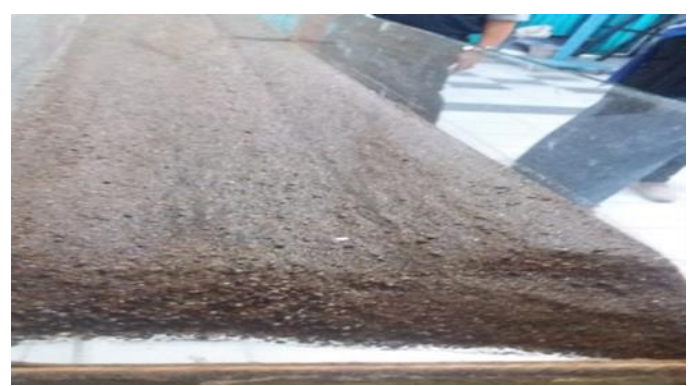

Figure 11. Erosion and Sedimentation Patterns On 30 Minute

Figure 11 is a pattern that occurs during the simulation time interval for 30 minutes and its results can be said to have occurred changes in the form of sediment transport at the upstream of Aur river with wave form starting from the side of the river.

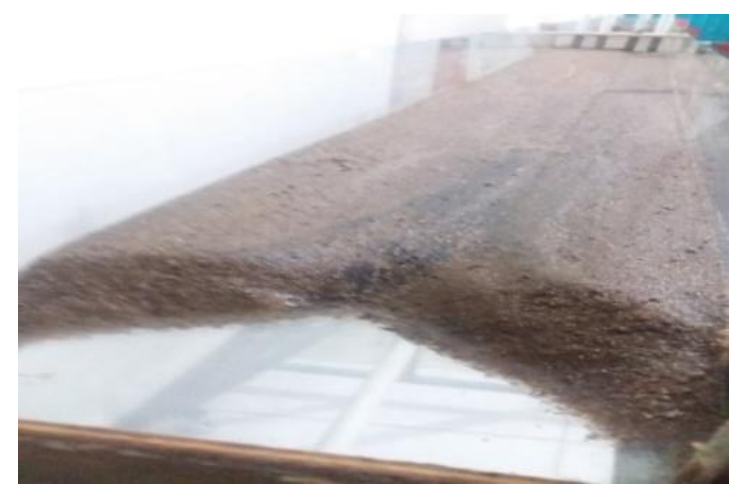

Figure 12. Erosion and Sedimentation pattern on 60 Minute

Figure 12 is a pattern that occurs during the simulation time interval for 60 minutes and its results can be said to have occurred changes in the form of sediment transport

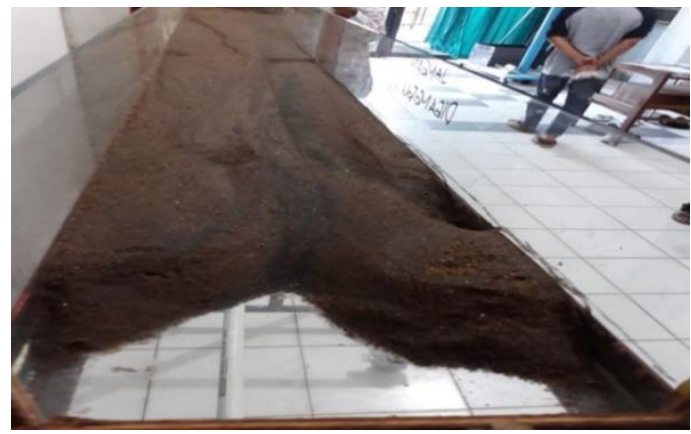

Figure 13. Erosion and Sedimentation Pattern on 90 Minute

In Figure 13 is a pattern that occurs during the simulation time interval for 90 minutes and its results can be said to have occurred changes in the form of sediment transport at the Aur River upstream. A larger wavy-shaped pattern is found in the direction of the river body and this is possible because of the greater flow rate moving in the center of the river body.

\section{CONCLUSION}

The basic sediments found at the upstream of the river at various directions appear, its happen because many factors influence the process of sediment distribution in the river mouth, that the delta deposit population will be more complex due to various currents, tides, river currents, waves and alternating directions turn back. The grain size distribution pattern with the type of silty sand indicates that there is a relationship between current and sediment distribution.

Based on the results of the model simulation, it is known that the sediment pattern conditions caused by weak water velocity will cause sediment particles with a larger size to be more easily deposited while smaller sediment particles will be deposited.

The results of the model simulation show that the erosion and sedimentation pattern that occurs is there is a lot of sediment build-up on the left side and erode in the middle. This shows that the influence of water velocity greatly affects the erosion and sediment pattern.

The amount of sediment transport that occurs at the Aur River upstream amounted to 7.48 cubic meter per day or 2.693 cubic meter per year at least done with the dredging period is every 7.5 months or 2.7 years by river body. Erosion and sedimentation pattern occurring at the upstream of the Aur River by the shaped "chute and Poll"

\section{SUGGESTION}

Further research is needed with a comparison from physical models and mathematical models due to validity process and perfect result.

It is necessary to socialize the utilization of Aur river wisely, so as not to interfere with the function and performance of the Aur River given the abundant activities of the local population in terms of economic 
activities around the river as a support for the lives of local residents.

It is necessary to check periodically for areas that are prone to flood run-off by looking at the movement of water level fluctuations in each cross-section of a particular river channel and the seriously anticipated rapid handling carried out by stakeholders related to flood mitigation by preparing pumps or by way of normalization to prevent flood runoff which is getting worse.

\section{REFERENCES}

Chalov, S. E. R. G. E. Y., \& Ermakova, G. A. L. I. N. A. 2011. Fluvial response to climate change: a case study of northern Russian rivers. Cold Region Hydrol. Chang. Climate. IAHS, 346, 111-119.

Collinson, J. 2019. Sedimentary structures. Dunedin Academic Press Ltd.

Gurnell, A. M., Corenblit, D., García de Jalón, D., González del Tánago, M., Grabowski, R. C., O'hare, M. T., \& Szewczyk, M. 2016. A conceptual model of vegetation-hydrogeomorphology interactions within river corridors. River research and applications, 32(2), 142-163.

Hewitt, G. 2013. Annular two-phase flow. Elsevier.

Ikhsan, C. 2017. Effect of Variation of water discharge on bed load rate on open channel with steady flow pattern, Civil Engineering Media, 2017, January 2017

Lamchuan, P, et al. 2020. Daily Suspended Sediment Load Estimation Using Multivariate Hydrological Data. International Journal of GEOMATE, April, 2020, Vol.18, Issue 68, pp. $1-8$

Shu, A. P., Tang, C., Zhang, X., Shao, S. D., \& Yang, K. 2015. Deposition morphology of non-homogeneous debris flow and its energy characteristics. Journal of mountain science, 12(5), 1157-1168.

Syarifudin, A., 2017. Environmentally Urban Drainage. Andi Publishing. pp 38-42

Syarifudin, A. 2017. The influence of Musi river sedimentation to the aquatic environment. In MATEC Web of Conferences (Vol. 101, p. 04026). EDP Sciences.

Walling, D. E., \& Collins, A. L. 2016. Fine sediment transport and management. River science: research and management for the $21 \mathrm{st}$ century. Wiley, London, 37-60.

Zhang, W., Xu, Y., Wang, Y., \& Peng, H. 2014. Modeling sediment transport and river bed evolution in river system. Journal of Clean Energy Technologies, 2(2), 175-179.

\section{ACKNOWLEDGEMENT}

We would like to thank Ir. Djarot Widyoko, MT, Director General of Water Resources, Ministry of Public Works and Housing of Indonesia, Dr. Sunda Ariana, M.Pd, MM, Rector of Universitas Bina Darma, and Ir. Suparji, S ST, MT Head of BBWSS-VIII Ministry of Public Work and Housing of Indonesia who are pleased to give permission and assistance to the author, especially in the preparation of the data so that the paper can be completed 